\title{
Measuring Digital Competence and ICT Literacy: An Exploratory Study of In-Service English Language Teachers in the Context of Saudi Arabia
}

\author{
Ahmed Abdulteeef M. Al Khateeb ${ }^{1}$ \\ ${ }^{1}$ College of Arts, King Faisal University, Al-Ahssa, Eastern Province, Kingdom of Saudi Arabia \\ Correspondence: Ahmed Abdulteeef M. Al Khateeb, College of Arts, King Faisal University, Al-Ahssa, Eastern \\ Province, Kingdom of Saudi Arabia. E-mail: ahmed_9114@hotmail.com
}

Received: June 12, 2017

doi:10.5539/ies.v10n12p38
Accepted: August 3, $2017 \quad$ Online Published: November 28, 2017

URL: https://doi.org/10.5539/ies.v10n12p38

\begin{abstract}
The purpose of this research is to measure in-service English language teachers' digital competence, particularly for the enhancement of teaching English as a second/foreign language in schools in Saudi Arabia. Information and communication technology (ICT) knowledge is currently considered as a vital skill for foreign language teachers in addition to their linguistic competence. Recently, there has been a focus on digital competence, since it can be regarded as a gateway for enriching knowledge, economies, societies and individuals. There is also a massive need for teachers to assess their own digital competence according to non-conventional norms (i.e., having the ability to share content and manage information). In light of this rationale, this paper investigates the following research question: to what extent are English language teachers in Saudi Arabia digitally competent and in what aspects? This study used a standardized questionnaire that was constructed using a validated comprehensive framework. This instrument was designed to assess the professional capability of English language teachers in terms of their willingness and readiness to use ICTs along with their current digital competence used throughout their teaching and educational practices. The research included a diverse range of participants who come from various backgrounds, genders and experiences. The study was concluded with a presentation of useful recommendations and key research questions for future research.
\end{abstract}

Keywords: digital competence, ICT literacy, in-service English language teachers, readiness, awareness, adaptation of web-based technologies

\section{Introduction}

\subsection{Introduce the Problem}

There has been growing interest among researchers across the globe in the areas of digital competence and information and communication technology (ICT). The concept of information communication and technology (ICT) intersects with the fundamental premises of digital competence. Nevertheless, the latter requires individuals to be able to retrieve, evaluate, store, present and exchange information and communication, as well as collaborate through the Internet and social networking tools. Digital competence does not only show the ability to make use of the wealth of new potentials associated with digital technologies and overcome the challenges they may involve, but it also indicates the meaningful participation in the emerging knowledge society of the twenty-first century. Undoubtedly, the diverse technologies (e.g., computer, interactive boards, apps ... etc.) that are influencing the life of consumers and users around the globe can be beneficial for the learning and teaching process as it may increase access to more education resources and reveal wider opportunities for collaboration and problem-solving.

\subsection{Explore Importance of the Problem}

Very importantly, using such reapidly growing technologies appropriately with the acquisition of the instrumental knowledge and skills for digital tools and media usage are amongst the conditions required to achieve digital competence. This intensive, exploratory research focuses on answering the following pivotal research question:

RQ1) To what extent are in-service English language teachers in Saudi Arabia are digitally competent and ICT 
users? and in what aspects?

\section{Literature Review}

\subsection{Digital Competence and ICT: Decoding the Puzzle}

Very recently, the need to normalize numerous evolving technologies, such as social networking tools, has dramatically increased. Sysoyev and Evstigneev (2015) also show that one of the principal reasons for adopting digital skills and ICT is because 'competency in the use of information and communication technologies is an integral part of a foreign language teachers' professional competency'. Therefore, ICT refers to different technologies that are responsible for handling telecommunications such as broadcast media and audio-visual processing and transmission systems.

Digital competence has been stated as one of the essential competencies in the European framework for key competencies for lifelong learning (Rantala and Suoranta, 2008). Those key competencies identified by the European Parliament and of the Council (2006) include: (1) communication in the mother tongue, 2) communication in foreign languages, (3) mathematical competence and basic competences in science and technology, 4) digital competence, 5) learning to learn, (6) social and civic competences, 7) a sense of initiative and entrepreneurship, and 8) cultural awareness and expression. A new framework for the development of digital competence was proposed in one of the European Commission reports (2013). The framework consists of five core areas: information processing, communication, content creation, problem solving, and safety. The information processing aspect measures users ability to 'identify, locate, retrieve, store, organise and analyse digital information, judging its relevance and purpose' while the communication criterion measures users potentiality to 'communicate in digital environments, share resources through online tools, link with others and collaborate through digital tools, interact with and participate in communities and networks, cross-cultural awareness'.

The term content-creation relates to users' talent to 'create and edit new content (from word processing to images and video); integrate and re-elaborate previous knowledge and content; produce creative expressions, media outputs and programming; and deal with and apply intellectual property rights and licenses'. Whereas, safety area also refer to learners' skills regarding 'personal protection, data protection, digital identity protection, security measures, safe and sustainable use'. Finally, problem-solving tests users' ability to identify digital needs and resources, make informed decisions as to which are the most appropriate digital tools according to the purpose or need, solve conceptual problems through digital means, their creative use of technologies, solve technical problems, and update one's own and others' competences. Those five areas of digital competence have been developed into a self-assessment gird according to three proficiency levels: basic, intermediate and advanced (see Appendix 1).

Yet, this concept, to some extent, is still confusing due to its interference with other several concepts which may share one or more of its functions. Part of this confusion is the fact that this area is multi-faceted and rapidly changing as new tools and technologies appear. Sometimes both of competence and skills are interpreted as being the same; however, competence is a more generic concept that involves more than skills whereas skills pay attention to social and emotional features of the use of technology as competence emphasizes. Digital competence has been described differently and no common globally-agreed definition exists (Ala-Mutka, 2011). Ferrari (2012) defined digital competence as the 'set of knowledge, skills, and attitudes... required when using ICT and digital media to perform tasks; ... and build knowledge'. This researcher extends the description of the concept as being the 'confident, critical and creative use of ICT to achieve goals related to work, employability, learning, leisure, inclusion and/or participation in society' (Ferrari, 2012, p: 1). The concept has been affected by plenty of others areas such as social and cultural skills.

In general, digital competence implies knowledge, awareness and attitudes towards the values of ICT along with owning the ability to deal with the latest technologies and digital information (Ferrari, 2013) where users are entitled to create, to manipulate, to design, and to self-actualize. Such capability is linked to cognitive-thinking strategies in terms of utilizing digital information and achieving tasks in digital environments. Jones and Flannigan (2006) characterize this ability as users are potential to:

use the computer's digital reproduction capability (copy and paste) in order to form genuine-creative products (reproduction literacy), the flexibility of thinking that enables learners to construct knowledge from hypertextual, non-linear navigation through knowledge domains (lateral literacy), and the ability to critically evaluate and assess the quality of digital information (information literacy) (p. 6). 


\subsection{Digital Literacy and Digital Competence}

In recent years, a number of concepts have been explored in the literature on the subject of the mastery of technology-related skills, including both digital competence and digital literacy. It is believed that digital literacy is a chief motive to digital competence. Literacy is a term that commonly refers to the ability to read and write text using traditional paper-based literacy and related literate practices (Belshaw, 2011). Yet, as a result of new digital technologies a new form of literacy has come into existence which requires users to combine knowledge by integrating sound and moving images, oral and written language, as well as $3 \mathrm{D}$ objects, by understanding their specific affordances, uses, and constraints (Leu, et. al., 2007).

Digital literacy has also been described as involving knowledge relevant to traditional literacy and media studies (Ilomäki, Kantosalo, \& Lakkala, 2011). While others interpret it if from a different perspective, for instance, Carrington (2005) states that digital literacy involves the transition of text from being printed to a new form of literacy (digitally-mediated); therefore, having the features on interactivity and openness. In short, digital literacy is a mixture of technical support alongside cognitive, emotional and social skills (Aviram \& Eshet-Alkalai, 2006). This form of literacy also refers to how technologies can assist users and play a number of important roles in their daily life, including social interaction; however, the complexity related to digital literacy also must be thought of particularly in terms of formalizing learning (Nixon \& Erstad, 2009). According to Alkali and Amichai-Hamburger (2004), digital literacy consists of five elements: photo-visual skills, reproduction skills, branching skills, information skills, and socio-emotional skills which all require an appropriate level of critical thinking and a wider understanding of media (Rantala \& Suoranta, 2008). In terms of digital competence, it is considered an essential component of the twenty first century (Ferrari, 2013). It involves skills which exceed searching for information online, and includes more demanding services and advanced expertise such as problem-solving, sharing and collaborating with peers (Griffin, McGraw, \& Care, 2012).

Digital competence relates to information given to the use of computer and electronic devices while digital literacy involves reading and understanding how to deal with media to produce digital representation, as well as gaining knowledge primarily through digital means (Jones-Kavalier \& Flannigan, 2008). It is believed that digital competence is not restricted to online-based knowledge, as it complements other forms of common literacies.

\subsection{Model of Digital Literacy}

As the use of ICT and digital tools continues to grow, Walker and White (2015) revealed a model whose design was based on Canale and Swain's (1980) model of linguistic competence. The current model of digital competence demonstrates a wide range of linguistic capabilities, in addition to digital knowledge and experience, including: procedural competence, social-digital competence, digital discourse competence and strategic competence. Such components of digital competence are essential for 'diagnosing, understanding, and repairing the digital needs of learners' (Walker \& White, 2015, p. 9).

\section{Method}

The term methodology is more than just looking at methods used for data collection, but also includes the concepts and theories underpinning those methods. The research methodology includes the criteria by which researchers go about their work in order to describe, explain and predict certain phenomena. It uses the quantitative approach of methodology to explore the following research question: to what extent are in-service English language teachers in Saudi Arabia digitally competent and ICT users? And in what aspects?

\subsection{Research Tool and Sampling}

A standardized questionnaire was adopted and was later administered and managed via one of the electronic survey platforms, SurveyMonkey. The questionnaire was designed and tested by the European Union (Europass) and a few necessary amendments were made in order to make it more suitable for the context and participants (see Appendix 1). This robust questionnaire was chosen because Ferrari (2013) states that the Digital Competence Framework for Citizens (DigComp) can support the improvement of digital skills of the European citizens as well as others located in different contexts. DigComp helps 'organisations, businesses and individuals to identify digital knowledge and the needs of digital culture that citizens have in their social and personal life' (Vuorikari et al., 2016). The current framework has already been used in European contexts by several institutions and individuals. Therefore, it was adopted for this research into in-service English language teachers in Saudi Arabia who have spent varying numbers of years teaching English as a foreign language at three basic levels (primary, intermediate and secondary). It consists of five main categories (i.e., Information processing, Communication, Control creation, Safety and Problem solving) which underline twenty-one competences. 
The total number of teachers who participated in this research was one hundred and ten (male and female) teachers across the Kingdom of Saudi Arabia. The participants were in-service English language teachers who work in primary, intermediate and secondary education. They all had at least several years teaching experience and come from different cultural and economic backgrounds. They were selected through a technique known as of purposive sampling. In purposive sampling, the researcher selects people who are keen to provide the appropriate information from their own experience and knowledge regarding the domain or issue under investigation (Bernard, 2002). The questionnaire was designed and distributed electronically using Survey Monkey to avoid any possible prejudice and to make sure that information about all the participants remained completely anonymous. The objectives and purposes of the study were clarified to the participants and they were requested to be as accurate as possible regarding how they see themselves in terms of their digital competence and their ability to deal with various technologies.

\subsection{Cronbach's Alpha: Reliability and Internal Consistency}

The reliability of any given measurement depends on the extent to which it is a consistent measure of a concept, and Cronbach's alpha is one way of measuring the strength of internal consistency. The resulting coefficient of reliability ranges from 0 to 1 when providing this overall assessment of a measure's reliability. If all of the scale items are entirely independent from one another (i.e., are not correlated or share no covariance), then the alpha $=$ 0 ; on the contrary, if all of the items have high covariances, then alpha will approach 1 as the number of items in the scale approaches infinity. The higher the alpha coefficients; the more the items have shared covariance and probably measure the same underlying concept. In this research, the Cronbach's alpha coefficient of 0.9013 is clearly acceptable, suggesting that the items have a relatively high internal consistency, as shown in Table 1 below (Note that a reliability coefficient of 0.7 or higher is considered 'acceptable' in most social science research and humanities-related studies). This would indicate strong intercorrelations (inter-connections) among test items.

Table 1. Output of reliability test items (Cronbach alpha)

\begin{tabular}{lcccccc}
\hline \multicolumn{7}{c}{ Test scale $=$ mean (standardized items) } \\
\hline Item & Obs & Sign & correlation & correlation & correlation & alpha \\
\hline Q7 & 107 & + & 0.4854 & 0.4044 & 0.3357 & 0.9010 \\
Q8 & 105 & + & 0.5598 & 0.4860 & 0.3282 & 0.8979 \\
Q9 & 107 & + & 0.5902 & 0.5254 & 0.3270 & 0.8974 \\
Q10 & 102 & + & 0.4742 & 0.3971 & 0.3344 & 0.9004 \\
Q11 & 102 & + & 0.7075 & 0.6586 & 0.3168 & 0.8930 \\
Q12 & 101 & + & 0.6173 & 0.5577 & 0.3233 & 0.8958 \\
Q13 & 102 & + & 0.6109 & 0.5498 & 0.3237 & 0.8960 \\
Q14 & 102 & + & 0.7770 & 0.7381 & 0.3114 & 0.8906 \\
Q15 & 100 & + & 0.6657 & 0.6113 & 0.3205 & 0.8946 \\
Q16 & 101 & + & 0.5921 & 0.5293 & 0.3256 & 0.8968 \\
Q17 & 100 & + & 0.4928 & 0.4212 & 0.3325 & 0.8997 \\
Q18 & 101 & + & 0.5977 & 0.5360 & 0.3248 & 0.8965 \\
Q19 & 101 & + & 0.7694 & 0.7292 & 0.3120 & 0.8909 \\
Q20 & 100 & + & 0.3408 & 0.2592 & 0.3441 & 0.9042 \\
Q21 & 101 & + & 0.5774 & 0.5138 & 0.3265 & 0.8972 \\
Q22 & 100 & + & 0.6980 & 0.6478 & 0.3179 & 0.8935 \\
Q23 & 101 & + & 0.6833 & 0.6316 & 0.3185 & 0.8938 \\
Q24 & 98 & + & 0.5962 & 0.5352 & 0.3247 & 0.8964 \\
Q25 & 101 & + & 0.6450 & 0.5888 & 0.3213 & 0.8950 \\
Test scale & & & & & 0.3247 & $\mathbf{0 . 9 0 1 3}$ \\
\hline
\end{tabular}

\section{Findings and Data Analysis}

\subsection{Subjects' Demographics}

As shown in Table 2, most of the participants have a major in English (93.52\%), with a bachelor qualification (80.37). Nearly half the participants teach in secondary schools $(45.79 \%)$, with a third having teaching 
experience of between five and ten years (33.64\%). There was also a balance identified between male (49.53\%) and female $(50.47 \%)$ participants. Interestingly, $60.75 \%$ of the subjects stated that they have certificates in computing and/or Information Technology. All of the participants work in government funded schools, since they are the target audience of this research.

Table 2. Subjects' demographics

\begin{tabular}{|c|c|c|c|}
\hline Question & Choice & Percentage & No. of participants \\
\hline \multirow{2}{*}{ Q1). What is your major degree - or background? } & English & $93.52 \%$ & 101 \\
\hline & Others & $6.48 \%$ & 7 \\
\hline \multirow{4}{*}{ Q2). What is your qualification? } & Diploma & $4.67 \% 5$ & 5 \\
\hline & Bachelor & $80.37 \%$ & 86 \\
\hline & Master & $13.08 \%$ & 14 \\
\hline & Others & $1.87 \% 2$ & 2 \\
\hline \multirow{3}{*}{ Q3). What is your gender? } & Male & $49.53 \%$ & 53 \\
\hline & Female & $50.47 \%$ & 54 \\
\hline & Primary & $27.10 \%$ & 29 \\
\hline \multirow[t]{2}{*}{ Q4). Which stage are you teaching? } & Intermediate & $27.10 \%$ & 29 \\
\hline & Secondary & $45.79 \%$ & 49 \\
\hline \multirow{2}{*}{$\begin{array}{l}\text { Q5). Do you have any computer or information technology (IT)-related } \\
\text { certificates? }\end{array}$} & No & $39.25 \%$ & 42 \\
\hline & Yes & $60.75 \%$ & 65 \\
\hline \multirow{4}{*}{ Q6). How many years of teaching experience do you have? } & From 1 - 5 years & $14.02 \%$ & 15 \\
\hline & From 5 - 10 years & $33.64 \%$ & 36 \\
\hline & From $10-15$ years & $31.78 \%$ & 34 \\
\hline & Others & $20.56 \%$ & 22 \\
\hline
\end{tabular}

\subsection{Descriptive and Inferential Analysis}

The questionnaire consisted of twenty-five questions, including those aimed at collecting demographic information and variables related to digital competence. There were three levels used to recognize digital competence and ICT literacy among in-service English language teachers in Saudi Arabia: basic, intermediate and advanced users.

The findings revealed that the teachers vary considerably in their level of digital competence and ICT awareness, the readiness in the adaptation of digitally-oritneted applications in the process of English language teaching. Indeed, it was discovered that the majority of teachers are basic users $(\mathbf{4 2 . 1 \% )}$ in the five areas provided: Information processing, communication, content creation, safety and problem solving, just over a third indicated they were intermediate users $(\mathbf{3 6 . 8 \%})$ and advanced users accounted for just over a quarter (26.3\%), as shown below in Table 3.

Table 3. Descriptive and inferential analysis of test items

\begin{tabular}{lcccc}
\hline Item test No. & Basic & Intermediate & Advanced & Total \\
\hline Q7 & 22 & 43 & 42 & 107 \\
& $21 \%$ & $40.2 \%$ & $39.3 \%$ & $100.0 \%$ \\
Q8 & 35 & 40 & 30 & 105 \\
& $33.3 \%$ & $38.1 \%$ & $28.6 \%$ & $100 \%$ \\
Q9 & 29 & 29 & 49 & 107 \\
& $27.1 \%$ & $27.1 \%$ & $45.8 \%$ & $100 \%$ \\
Q10 & 19 & 16 & 67 & 102 \\
& $18.6 \%$ & $15.7 \%$ & $65.7 \%$ & $100 \%$ \\
Q11 & 38 & 28 & 36 & 102 \\
& $37.3 \%$ & $27.5 \%$ & $35.3 \%$ & $100 \%$ \\
Q12 & 18 & 29 & 54 & 101 \\
& $17.8 \%$ & $28.7 \%$ & $53.5 \%$ & $100 \%$ \\
Q13 & 24 & 39 & 39 & 102 \\
& $23.5 \%$ & $38.2 \%$ & $38.2 \%$ & $100 \%$ \\
\hline
\end{tabular}




\begin{tabular}{ccccc}
\hline Q14 & 52 & 33 & 17 & 102 \\
& $51.0 \%$ & $32.4 \%$ & $16.7 \%$ & $100 \%$ \\
Q15 & 35 & 33 & 32 & 100 \\
& $35.0 \%$ & $33.0 \%$ & $32.0 \%$ & $100 \%$ \\
Q16 & 40 & 34 & 27 & 101 \\
& $39.6 \%$ & $33.7 \%$ & $26.7 \%$ & $100 \%$ \\
Q17 & 54 & 31 & 15 & 100 \\
& $54.0 \%$ & $31.0 \%$ & $15.0 \%$ & $100 \%$ \\
Q18 & 40 & 35 & 26 & 101 \\
& $39.6 \%$ & $34.7 \%$ & $25.7 \%$ & $100 \%$ \\
Q19 & 36 & 34 & 31 & 101 \\
& $35.6 \%$ & $33.7 \%$ & $30.7 \%$ & $100 \%$ \\
Q20 & 26 & 38 & 36 & 100 \\
& $26.0 \%$ & $38.0 \%$ & $36.0 \%$ & $100 \%$ \\
Q21 & 23 & 56 & 22 & 101 \\
& $22.8 \%$ & $55.4 \%$ & $21.8 \%$ & $100 \%$ \\
Q22 & 36 & 38 & 26 & 100 \\
& $36.0 \%$ & $38.0 \%$ & $26.0 \%$ & $100 \%$ \\
Q23 & 36 & 28 & 37 & 101 \\
& $35.6 \%$ & $27.7 \%$ & $36.6 \%$ & $100 \%$ \\
Q24 & 32 & 39 & 27 & 98 \\
& $32.7 \%$ & $39.8 \%$ & $27.6 \%$ & $100 \%$ \\
Q25 & 41 & 35 & 25 & 101 \\
& $40.6 \%$ & $34.7 \%$ & $24.8 \%$ & $100 \%$ \\
\hline & & & & \\
& & & &
\end{tabular}

The statistical analysis showed that most subjects, who completed the survey, were found to have only a basic digital competence when dealing with different software settings and functions, and update their digital and ICT-related skills on a regular basis (Qs 14, 17, 25). On the contrary, most participants were discovered to possess an intermediate level of competence when it came to solving problems related to technical support (Qs 21). Most than half of the subjects were found to be competently advanced users of cloud computing and wide range of communication tools and social networking applications (Qs 9, 10, 12). It was also found that the participated teachers who participated in the study have an equal level of competence, to some extent, in the following: being aware of social networking sites and online collaboration tools, passing on or sharing knowledge with others online, and using advanced features of communication tools such as video conferencing (Q13).

In addition, the teachers responded very similarly in terms of knowing what digital tools can help in solving problems, using digital technologies to solve (non-technical) problems, and frequently choosing the right tool, device or application to solve non-technical problems (Q23). In terms of teachers' responses to the questions provided in the questionnaire, all of the participants (107) completed questions seven (Q7) and nine (Q9) whereas question twenty-four (Q 24) was only completed by ninety-eight (89\%) teachers.

As indicated below, Figure 1 summarizes various responses from the teachers that indicate their digital expertise and ICT literacy. It is noticeable that teachers were found to be advanced in the use of a range of communication tools such e-mail, instant messaging, blogs, and other common social networks such as Twitter and Facebook. However, the teachers were discovered to have a basic level of competence with regard to the use of online service such as e-banking. 


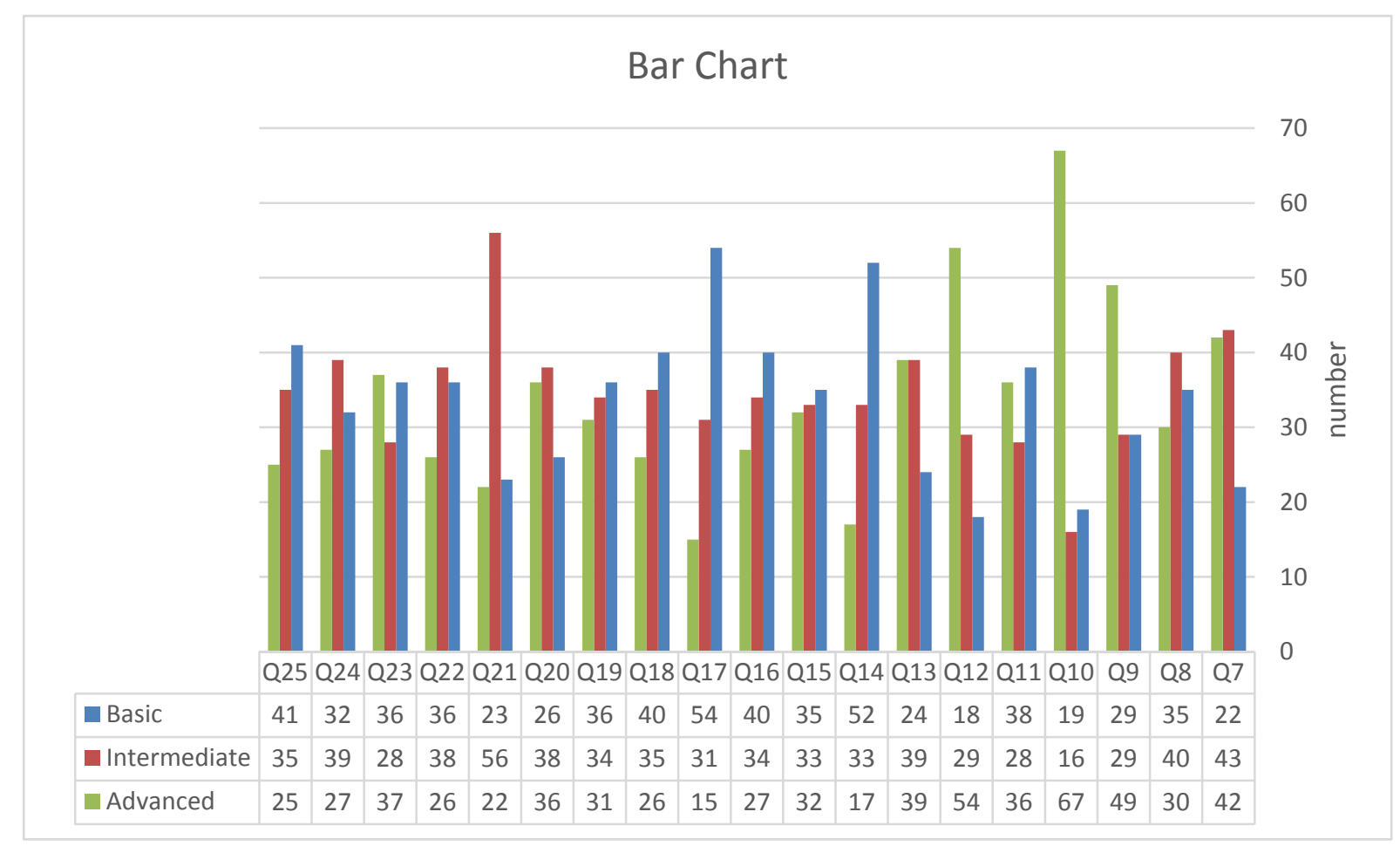

Figure 1. In-service teachers' responses with regard to their digital expertise and ICT literacy

\subsection{Polychoric Correlation and Matrix}

Polychoric correlation is a statistical test used to measure the correlation coefficient (association) between two ordinal variables. The variables are scored from a number of multiple-choice questions (from Q7 to Q 25 as shown in appendix 1). The purpose of polychoric correlation is to reduce the effect of statistical artifact and sets an assumption of an underlying joint continuous distribution. The coefficient is between 0 and 1 where zero does not indicate any relationship and one signifying perfect relationship.

As indicated in Table 4, all the variables which achieved polychoric correlation were indicated with bold. This means a strong agreement between various test items. Those test items or questions numbered from 7 to 25 (as shown in Appendix A) have achieved what is so-called polychoric correlation at various levels. For instance, there is a correlation coefficient with a level of $>(0.4)$ and higher of two normally distributed variables such as Q15 and Q19 (0.73). 
Table 4. Output of correlation coefficient analysis of test items

\begin{tabular}{|c|c|c|c|c|c|c|c|c|c|c|c|c|c|c|c|c|c|c|c|}
\hline & Q7 & Q5 & Q9 & Q10 & Q11 & Q12 & Q13 & Q14 & Q15 & Q16 & Q17 & Q18 & Q19 & Q20 & Q21 & Q22 & Q23 & Q24 & Q25 \\
\hline Q7 & 1 & & & & & & & & & & & & & & & & & & \\
\hline Q9 & 0.37 & 1 & & & & & & & & & & & & & & & & & \\
\hline Q9 & 0.24 & 0.56 & 1 & & & & & & & & & & & & & & & & \\
\hline Q10 & 0.17 & 0.21 & 0.43 & 1 & & & & & & & & & & & & & & & \\
\hline Q11 & 0.41 & 0.48 & 0.57 & 0.55 & 1 & & & & & & & & & & & & & & \\
\hline Q12 & 0.34 & 0.57 & 0.56 & 0.44 & 0.52 & 1 & & & & & & & & & & & & & \\
\hline Q13 & 0.32 & 0.39 & 0.35 & 0.50 & 0.54 & 0.60 & 1 & & & & & & & & & & & & \\
\hline Q14 & 0.32 & 0.55 & 0.54 & 0.41 & 0.77 & 0.55 & 0.65 & 1 & & & & & & & & & & & \\
\hline Q15 & 0.17 & 0.44 & 0.40 & 0.37 & 0.46 & 0.40 & 0.43 & 0.65 & 1 & & & & & & & & & & \\
\hline Q16 & 0.28 & 0.32 & 0.30 & 0.06 & 0.52 & 0.43 & 0.33 & 0.57 & 0.36 & 1 & & & & & & & & & \\
\hline Q17 & 0.39 & 0.29 & 0.11 & 0.14 & 0.38 & 0.30 & 0.37 & 0.62 & 0.51 & 0.55 & 1 & & & & & & & & \\
\hline Q18 & 0.34 & 0.30 & 0.37 & 0.16 & 0.51 & 0.33 & 0.49 & 0.61 & 0.38 & 0.37 & 0.53 & 1 & & & & & & & \\
\hline Q19 & 0.37 & 0.47 & 0.39 & 0.45 & 0.65 & 0.45 & 0.47 & 0.73 & 0.65 & 0.53 & 0.35 & 0.56 & 1 & & & & & & \\
\hline Q20 & -0.02 & -0.05 & 0.22 & 0.21 & 0.10 & 0.28 & 0.07 & 0.21 & 0.12 & 0.19 & -0.02 & 0.05 & 0.21 & 1 & & & & & \\
\hline Q21 & 0.23 & 0.17 & 0.19 & 0.47 & 0.35 & 0.41 & 0.43 & 0.45 & 0.40 & 0.22 & 0.28 & 0.47 & 0.68 & 0.08 & 1 & & & & \\
\hline Q22 & 0.26 & 0.39 & 0.40 & 0.31 & 0.58 & 0.43 & 0.43 & 0.59 & 0.54 & 0.44 & 0.51 & 0.60 & 0.71 & 0.15 & 0.53 & 1 & & & \\
\hline Q23 & 0.21 & 0.34 & 0.47 & 0.37 & 0.68 & 0.48 & 0.53 & 0.71 & 0.45 & 0.39 & 0.28 & 0.63 & 0.63 & 0.18 & 0.60 & 0.46 & 1 & & \\
\hline Q24 & 0.15 & 0.30 & 0.36 & 0.31 & 0.41 & 0.44 & 0.25 & 0.49 & 0.57 & 0.47 & 0.45 & 0.30 & 0.52 & 0.20 & 0.44 & 0.54 & 0.39 & 1 & \\
\hline Q25 & 0.37 & 0.28 & 0.44 & 0.34 & 0.60 & 0.32 & 0.49 & 0.60 & 0.55 & 0.45 & 0.49 & 0.59 & 0.65 & 0.26 & 0.33 & 0.50 & 0.58 & 0.35 & 1 \\
\hline
\end{tabular}

\subsection{Factor Analysis}

Factor Analysis is a statistical method used to describe variability among different variables (Q7 - Q25) for the purpose of reducing data and to concentrate on variation of a large number of observed variables into far fewer aggregated dimensions. Eigenvalue reflects the number of extracted factors whose sum should be equal to the number of test items which are subjected to factor analysis. The Eigenvalue is calculated for each factor extracted. If the Eigenvalue drops below 1, it means that the factor explains less variance than adding a variable would do. Accordingly, the findings showed the choice of 4 factors (eigenvalue $>=1$ ). These factors explain $57.21 \%$ of the variance. The first factor accounts for $37.12 \%$ of the variance, the second $7.52 \%$, the third $6.52 \%$ and the fourth $6.05 \%$. All the remaining factors are not statistically significant. After extracting the factors; the oblique rotation was used to ensure that the factors are orthogonal and better fit with the data.

The results of the principal-component factor analysis are given respectively starting with Q7 (item test 7) to Q 25 (item test 25) as shown in Table 5. Each principal component (axis) explains a linear combination of a group of interrelated variables which make the greatest contribution to the factor (or latent variable). The first four axis, or variables which each one was significantly found as a combination of a number of other variables which were also highly correlated, are as follows:

Factor 1, which involves test items or questions No. 10, 13, 18, 19, 21, 23 and 25;

Factor 2 which comprises of test items or questions No. 8, 9, 11 and 12;

Factor 3 which includes 14, 15, 16, 17, 22 and 24;

Factor 4 which consists of the following test items or questions No. 7 and 20 (see Appendix A for more details regarding the questions given and what each question is concerned with). These factors can be used as variables for further analysis. 
Table 5. Output of principal-component factor analysis

\begin{tabular}{cccccc}
\hline Variable & Factor1 & Factor2 & Factor3 & Factor4 & Uniqueness \\
\hline Q7 & & & & -0.4503 & 0.5504 \\
Q8 & & 0.8095 & & & 0.3673 \\
Q9 & & 0.7824 & & & 0.3797 \\
Q10 & 0.5873 & & & & 0.4449 \\
Q11 & & 0.4329 & & & 0.4088 \\
Q12 & & 0.6963 & & & 0.4190 \\
Q13 & 0.5195 & & & & 0.4896 \\
Q14 & & & 0.4177 & & 0.3515 \\
Q15 & & & 0.4312 & & 0.5227 \\
Q16 & & & 0.7373 & & 0.4215 \\
Q17 & & & 0.8113 & & 0.3431 \\
Q18 & 0.5799 & & & & 0.4193 \\
Q19 & 0.5863 & & & & 0.3468 \\
Q20 & & & & 0.7367 & 0.4324 \\
Q21 & 0.8993 & & & & 0.3750 \\
Q22 & & & 0.4374 & & 0.4628 \\
Q23 & 0.6988 & & & & 0.4189 \\
Q24 & & & 0.5439 & & 0.4389 \\
Q25 & 0.4124 & & & & 0.5378 \\
\hline
\end{tabular}

\section{Discussion}

The purpose of this research is to examine teachers' ability to apply a critical approach, as well as the necessary knowledge and skills necessary to plan, implement, evaluate and develop ICT-based courses. Moreover, the current research focuses on teachers, rather than learners, since they are the agents of change and play key role in changing learners' educational practices. It was decided that teachers, not learners, make up the participants in this study because digital competence and ICT-related skills cannot be introduced to schools or learners without the participation of teachers and their adequate experience in this area. Mastering the skills and professional knowledge-related to digital competence and ICT literacy has become necessary for teachers, language teachers in particular, in order that they can be integrated in curricula and employed during classes.

The outcomes of the current research revealed that the majority of teachers are not adequately digitally competent according to the level and standards required to enable them to be good digital teachers of the twenty-first century. Digital competence is associated with three knowledge areas which must be integrated: technology proficiency, pedagogical compatibility and social awareness (Zhao et al., 2002). Instefjord and Munthe (2016) confirm that teachers' digital competence is based on the knowledge areas suggested by Zhao et al. (2002).

In view of that, technology proficiency depends on teachers' technical competence and confidence in terms of employing technology. In addition, pedagogical compatibility relates to teachers' understanding of how technology can help in practice in the classroom and contribute to achieving the curriculum's goals. Finally social awareness refers to teachers' ability to deal with various social aspects of the school or class culture (Instefjord \& Munthe, 2016). Therefore, it was not surprising that a number of in-service English language teachers were found not to be advanced in terms of their digital competence due to 'inexperience, lack of training, lack of prior knowledge, or just being poor performing individuals' (Maderick et al., 2016, p. 343). There was a deficiency in didactic ICT skills, multifaceted digital leaning strategies and digital building.

Moreover, Garcia-Perez, Rebollo-Catalan, and Garcia-Perez (2016) observed that a number of teachers in general education showed a moderate level of digital competence with regard to using virtual social networking tools, yet their actual digital competence when teaching was found to be far less developed. In a different study, Røkenes and Krumsvik (2016) found that developments in teaching ESL with an advanced level of digital competence may depend on several factors such as access to support and resources, modeling, scaffolding learning experiences, linking theories with practice, reflection, innovative assessment practices, and collaborative learning. As demonstrated above, nearly an equal proportion of responses were provided by males and females, which would indicate less biased findings. Furthermore, most teachers who revealed their level of digital competence and their needs had from five to fifteen years of teaching experience. 
The findings show that despite the fact that the majority of the teachers had certificates in ICT; they assessed themselves as less competent in several aspects of digital competence. Nevertheless, this does not necessarily mean that other teachers with more or less years of teaching experience are uniquely different. The statistical analysis also showed a strong correlation (with a score of 0.73 ) between the ability to edit the content produced by others such as adding and deleting and the ability to increase awareness of the users' private information and credentials e.g., username and password.

\section{Recommendation and Conclusion}

The term competence is believed to be more complex than literacy as it heavily depends on acquiring more knowledge and skills than on access and use. Accordingly, and based on the findings drawn from the study, the teachers are required to appropriate the use of technologies. Ferrari (2012) views appropriation as the process that entails interaction with technologies, understanding them and using them. Digital competence has become a major concern in academia as a result of the advent of different communication tools. Indeed, they have become an essential part in teachers' life inside and outside classes. There is a tremendous necessity to introduce digital competence and IT-related issues into school curricula, assessment tests and classroom practice. Nearly $25 \%$, who have only been found with a wide knowledge and extensive awareness of digital competence and its underpinning practices such as using collaborative tools and learning management systems.

The teachers who took part in this research were identified as less digitally competent as they are expected to be. Further digital-related competencies should be promoted to teachers as part of continuous professional development (CPD). Such competencies also need to be incorporated into different teacher education programmes. CPD for both in-service and pre-service English language teachers and teacher educators must ensure that the necessary technological and curricula changes are taking place. Massive Open Online Courses (MOOCs) are just one way to support individuals' digital competence and encourage their unlimited participation on the web.

The relevant departments should offer teachers and teacher educators as well as learners access to various technological tools, along with the provision of sufficient training, knowledge and skills. In addition, in their strategic plans and policies academic institutions must promote the positive role of transformation, creativity, innovation and sharing of resources. There should also be serious attempts made to bridge what is known as the digital divide in teachers; particularly among English language teachers. The term digital divide refers to the gap existing between those who access computers and other ICT technologies and those who do not.

Further research should be carried out to investigate English language teachers' digital competence qualitatively to get further answers regarding the challenges that hinder and demotivate in-service English language teachers from integrating technology in English language classes in schools and other educational institutions. It would also be interesting to ask such teachers how they can become more digitally competent and better ICT users. The current research focused on determining the teachers' digital competence as individuals, rather than in groups or during social interaction. Thus, measuring and assessing teachers in those situations could be considered in other studies.

\section{References}

Ala-Mutka, K. (2011). Mapping digital competence: Towards a conceptual understanding. Sevilla: Institute for Prospective Technological Studies. European Commision-Joint Research Centre. Retrieved from https://pdfs.semanticscholar.org/6282/f40a4146985cfef2f44f2c8d45fdb59c7e9c.pdf.

Alkali, Y. E., \& Amichai-Hamburger, Y. (2004). Experiments in digital literacy. CyberPsychology and Behavior, 7(4), 421-429. https://doi.org/10.1089/cpb.2004.7.421

Aviram, A., \& Eshet-Alkalai, Y. (2006). Towards a theory of digital literacy: three scenarios for the next steps. European Journal of Open, Distance and E-Learning, 9(1). Retrieved from http://www.eurodl.org/index.php? $\mathrm{p}=$ archives\&year $=2006 \&$ halfyear $=1 \&$ article $=223$

Belshaw, D. (2011). What is 'digital literacy'? A Pragmatic Investigation. Durham University. Retrieved from http://etheses.dur.ac.uk/3446/1/Ed.D._thesis_(FINAL_TO_UPLOAD).pdf?DDD29

Bernard, H. R. (2002). Research Methods in Anthropology: Qualitative and Quantitative Methods (3rd ed.). AltaMira Press, Walnut Creek, California.

Carrington, V. (2005). The uncanny: digital texts and literacy. Language and Education, 19(6), 467-482. https://doi.org/10.1080/09500780508668698

Ferrari, A. (2012). Digital Competence in Practice: An analysis of frameworks. Sevilla: JRC IPTS. Retrieved 
from https://www.researchgate.net/profile/Yves_Punie/publication/256460731_Lecture_Notes_in_Compute r_Science/links/55a676dc08ae92aac77f28bd/Lecture-Notes-in-Computer-Science.pdf

Ferrari, A. (2013). DigComp: A framework for developing and understanding digital competence in Europe. Retrieved from http://digcomp.org.pl/wp-content/uploads/2016/07/DIGCOMP-1.0-2013.pdf

Garcia-Perez, R., Rebollo-Catalan, A., \& Garcia-Perez, C. (2016). The relationship between teacher training preferences and their digital skills on social networks. BORDON-REVISTA DE PEDAGOGIA, 68(2), $137-153$.

Griffin, P., McGraw, B., \& Care, E. (Eds.) (2012). Assessment and Teaching of $21^{\text {st }}$ Century Skills. Dordrech: Springer. https://doi.org/10.1007/978-94-007-2324-5

Ilomäki, L., Kantosalo, A., \& Lakkala, M. (2011). What is digital competence? Linked portal. Brussels: European Schoolnet (EUN), 1-12. Retrieved from https://helda.helsinki.fi/bitstream/handle/10138/154423/ Ilom_ki_etal_2011_What_is_digital_competence.pdf? sequence $=1$.

Jones, B., \& Flannigan, L. (2006). Connecting the digital dots: Literacy of the $21^{\text {st }}$ Century. Educause Quarterly, 29(2), 8-10. Retrieved from https://pdfs.semanticscholar.org/c2fb/d52466a35cd62d1476a9840e5064e88118c 4.pdf

Jones-Kavalier, B. R., \& Flannigan, S. I. (2008). Connecting the digital dots: Literacy of the 21st century. Teacher Librarian, 35(3), 13. Retrieved from http://er.educause.edu/ /media/files/article-downloads/ eqm0621.pdf

Leu, D. J., Zawilinski, L., Castek, J., Banerjee, M., Housand, B. C., Liu, Y., \& O’Neil, M. (2007). What is new about the new literacies of online reading comprehension? In secondary school literacy: What research reveals for classroom practice (pp. 37-68). Retrieved from http://geoc.uconn.edu/wp-content/uploads/sites/161/2013/08/NewLiteracies_article.pdf

Maderick, J. A., Zhang, S., Hartley, K., \& Marchand, G. (2016). Preservice teachers and self-assessing digital competence. Journal of Educational Computing Research, 54(3), 326-351. https://doi.org/10.1177/0735633115620432.

Nixon, H., \& Erstad, O. (2009). Reviewing approaches and perspectives on "digital literacy". Pedagogies: An International Journal, 4(2), 107-125. https://doi.org/10.1080/15544800902741556

Rantala, L., \& Suoranta, J. (2008). Digital literacy policies in the EU-inclusive partnership as the final stage of governmentality. Digital literacies: Concepts, policies and practices, 91-117. Retrieved from https://www.researchgate.net/profile/Juha_Suoranta/publication/274316556_Digital_Literacy_Policies_in_t he_EU-Inclusive_Partnership_as_the_Final_Stage_of_Governmentality/links/551bb0f10cf251 c35b50a199/ Digital-Literacy-Policies-in-the-EU-Inclusive-Partnership-as-the-Final-Stage-of-Governmentality.pdf

Røkenes, F. M., \& Krumsvik, R. J. (2016). Prepared to teach ESL with ICT? A study of digital competence in Norwegian teacher education. Computers and Education, 97, 1-20. https://doi.org/10.1016/j.compedu.2016.02.014

Sysoyev, P. V., Evstigneeva, I. A., \& Evstigneev, M. N. (2015). The Development of Students' Discourse Skills via Modern Information and Communication Technologies. Procedia-Social and Behavioral Sciences, 200, 114-121. https://doi.org/10.1016/j.sbspro.2015.08.028

Vuorikari, R., Punie, Y., Gomez, S. C., \& Van Den Brande, G. (2016). DigComp 2.0: The Digital Competence Framework for Citizens. Update Phase 1: The Conceptual Reference Model. Retrieved from http://publications.jrc.ec.europa.eu/repository/bitstream/JRC101254/jrc101254_digcomp\%202.0\%20the\%2 0digital $\% 20$ competence $\% 20$ framework\%20for\%20citizens.\%20update $\% 20$ phase $\% 201$.pdf

Walker, A., \& White, G. (2015). Technology-enhanced Language Learning: Connecting Theory and Practice. Oxford: Oxford University Press.

Zhao, Y., Pugh, K., Sheldon, S., \& Byers, J. L. (2002). Conditions for classroom technology innovations. Teachers college record, 104(3), 482-515. https://doi.org/10.1111/1467-9620.00170 


\section{Appendix A}

\section{The Digital Competence Questionnaire (adopted from UNISCO with little adaptation)}

\section{Category 1: Information processing}

Q7). In terms of information processing category, which one of the following would describe you the best:

- I can look for information online using a search engine.

- I can use different search engines to find information.

- I can use advanced search strategies to find reliable information on the internet such as using web feeds (like RSS).

Q8). In terms of information processing category, which one of the following would describe you the best:

- I know not all online information is reliable.

- I use some filters when searching to compare and assess the reliability of the information I find.

- I can assess the validity and credibility of information using a range of criteria.

Q9). In terms of information processing category, which one of the following would describe you the best:

- I can save or store files or content and retrieve them once saved or stored.

- I classify the information in a methodical way using folders. I backups of information or files I have stored.

- I can save information found on the internet in different formats. I can use cloud information storage services.

\section{Category 2: Communication}

Q10). In terms of communication category, which one of the following would describe you the best:

- I can communicate with others using Skype or chat -using basic features (e.g. voice messaging, SMS, text exchange).

- I can use advanced features of several communication tools (e.g. using Skype and sharing files).

- I actively use a wide range of communication tools (e-mail, chat, SMS, instant messaging, blogs, micro-blogs, social networks) for online communication.

Q11). In terms of communication category, which one of the following would describe you the best:

- I can share files and content using simple tools.

- I can use collaboration tools and contribute to e.g. shared documents/files someone else has created.

- I can create and manage content with collaboration tools (e.g. project management systems, online spreadsheets).

Q12). In terms of communication category, which one of the following would describe you the best:

○ I know I can use online services (e.g., e-banking, e-governments, e-hospitals...etc.).

○ I use features of online services (e.g. public services, e-banking, online shopping ...etc.).

- I actively participate in online spaces and use several online services (e.g. public services, e-banking, online shopping...etc.).

Q13). In terms of communication category, which one of the following would describe you the best:

- I am aware of social networking sites and online collaboration tools.

- I pass on or share knowledge with others online (e.g. via social networking tools or in online communities).

- I can use advanced features of communication tools (e.g. video conferencing, data sharing, application sharing).

\section{Category 3: Content creation}

Q14). In terms of content creation category, which one of the following would describe you the best:

- I can produce simple digital content (e.g. text, tables, images, audio files) in at least one format using digital tools. 
- I can produce complex digital content in different formats (e.g. text, tables, images, audio files). I can use tools for creating webpages or blogs.

- I can produce complex, multimedia content in different formats, using a variety of digital tools and environments. I can create a website using a programming language.

Q15). In terms of content creation category, which one of the following would describe you the best:

- I can make basic editing to content produced by others (e.g., adding and deleting).

- I can apply basic formatting (e.g. insert footnotes, charts, tables) to the content I or others have produced.

- I can use advanced formatting functions of different tools (e.g. mail merge, merging documents of different formats, using advanced formulas, macros).

Q16). In terms of content creation category, which one of the following would describe you the best:

I I know that content can be covered by copyright.

- I know how to reference and reuse content covered by copyright.

- I know how to - and when is necessary to - apply licenses and copyrights.

Q17). In terms of content creation category, which one of the following would describe you the best:

I I can modify simple functions of software and applications as changing default settings.

I know the basics - principles- of one programming language.

- I can use several programming languages. I know how to design, create and modify databases with a computer tool.

\section{Category 4: Safety}

Q18). In terms of safety category, which one of the following would describe you the best:

- I can take basic steps to protect my devices (e.g. using anti-viruses and passwords).

- I have installed security programmes on the device(s) that I use to access the Internet (e.g. antivirus, firewall).

- I frequently check the security configuration and systems of my devices and/or of the applications I use on a regular basis to access the Internet.

Q19). In terms of safety category, which one of the following would describe you the best:

- I am aware that my credentials (username/password) can be stolen. I know I should not reveal private information online.

I I use different passwords to access equipment, devices and digital services and I modify them on a periodic basis.

- I know how to react if my computer is infected by a virus. I can configure or modify the firewall and security settings of my digital devices.

Q20). In terms of safety category, which one of the following would describe you the best:

- I know that using digital technology too extensively can affect my health.

- I understand the health risks associated with the use of digital technology (e.g., risk of addiction).

- To avoid health problems (physical and psychological), I can make use of information and communication technology.

Q21). In terms of safety category, which one of the following would describe you the best:

- I take basic measures and actions to save energy.

- I understand the positive and negative impact of technology on the environment.

I I have an informed stance on the impact of digital technologies on everyday life and the environment.

\section{Category 5: Problem solving}

Q22). In terms of problem solving category, which one of the following would describe you the best: 
- I find support when a technical problem occurs or when using a new program.

- I can solve most of the more frequent problems that arise when using digital technologies.

- I can solve almost all problems that arise when using digital technology.

Q23). In terms of problem solving category, which one of the following would describe you the best:

- I know that digital tools can help me in solving problems.

- I can use digital technologies to solve (non-technical) problems.

- I can frequently choose the right tool, device, application, software or service to solve (non-technical) problems.

Q24). In terms of problem solving category, which one of the following would describe you the best:

- When confronted with a technological problem, I can use tools I know to solve it.

- I can solve technological problems by exploring the settings and options of programmes or tools.

- I am aware of new technological developments. I understand how new tools work.

Q25). In terms of problem solving category, which one of the following would describe you the best:

- I am aware that I need to update my digital skills regularly.

- I regularly update my digital skills. I am aware of my limits and try to fill my gaps.

- I frequently update my digital skills to decrease my limits and increase my digital knowledge.

\section{Many thanks for participation}

Best wishes

\section{Copyrights}

Copyright for this article is retained by the author(s), with first publication rights granted to the journal.

This is an open-access article distributed under the terms and conditions of the Creative Commons Attribution license (http://creativecommons.org/licenses/by/4.0/). 